University of Nebraska - Lincoln

DigitalCommons@University of Nebraska - Lincoln

Publications, Agencies and Staff of the U.S.

Department of Commerce

U.S. Department of Commerce

2009

\title{
Demography and population viability of polar bears in the Gulf of Boothia, Nunavut
}

\author{
Mitchell Taylor \\ Department of the Environment, Government of Nunavut Igloolik, Nunavut, Canada \\ Jeff Laake \\ National Marine Mammal Laboratory, Alaska Fisheries Science Center, National Marine Fisheries Service, \\ Seattle, Washington \\ Philip McLoughlin \\ University of Saskatchewan, 112 Science Place, Saskatoon, Saskatchewan S7N 5E2, Canada \\ H. Dean Cluff \\ Department of Resources, Wildlife, and Economic Development, Government of the Northwest Territories, \\ Yellowknife, Northwest Territories, Canada \\ Francois Messier \\ University of Saskatchewan, 112 Science Place, Saskatoon, Saskatchewan S7N 5E2, Canada
}

Follow this and additional works at: https://digitalcommons.unl.edu/usdeptcommercepub

Part of the Environmental Sciences Commons

Taylor, Mitchell; Laake, Jeff; McLoughlin, Philip; Cluff, H. Dean; and Messier, Francois, "Demography and population viability of polar bears in the Gulf of Boothia, Nunavut" (2009). Publications, Agencies and Staff of the U.S. Department of Commerce. 196.

https://digitalcommons.unl.edu/usdeptcommercepub/196

This Article is brought to you for free and open access by the U.S. Department of Commerce at DigitalCommons@University of Nebraska - Lincoln. It has been accepted for inclusion in Publications, Agencies and Staff of the U.S. Department of Commerce by an authorized administrator of DigitalCommons@University of Nebraska - Lincoln. 
MARINE MAMMAL SCIENCE, 25(4): 778-796 (October 2009)

(C) 2009 by the Society for Marine Mammalogy

DOI: $10.1111 / j .1748-7692.2009 .00302 . x$

This article is a U.S. government work, and is not subject to copyright in the United States.

\title{
Demography and population viability of polar bears in the Gulf of Boothia, Nunavut
}

\author{
MitCHELL K. TAYLOR \\ Department of the Environment, \\ Government of Nunavut, \\ P. O. Box 209, Igloolik, \\ Nunavut X0A OLO, Canada \\ JEFF LAAKE \\ National Marine Mammal Laboratory, \\ Alaska Fisheries Science Center, \\ National Marine Fisheries Service, \\ Seattle, Washington 98115, U.S.A.

\section{Philip D. MCLOUGHLIN} \\ Department of Biology, \\ University of Saskatchewan, \\ 112 Science Place, \\ Saskatoon, Saskatchewan S7N 5E2, Canada \\ E-mail: philip.mcloughlin@usask.ca

\section{H. Dean Cluff} \\ Department of Resources, Wildlife, and Economic Development, \\ Government of the Northwest Territories, \\ Yellowknife, Northwest Territories X1A 2P9, Canada

\section{FranÇOIS MESSIER} \\ Department of Biology, \\ University of Saskatchewan, \\ 112 Science Place, \\ Saskatoon, Saskatchewan S7N 5E2, Canada
}

\begin{abstract}
We estimated demographic parameters and harvest risks for polar bears (Ursus maritimus) inhabiting the Gulf of Boothia, Nunavut, from 1976 to 2000. We computed survival and abundance from capture-recapture and recovery data (630 marks) using a Burnham joint live-dead model implemented in program MARK. Annual mean total survival (including harvest) was $0.889 \pm 0.179(\bar{x} \pm 1 \mathrm{SE})$ for cubs, $0.883 \pm 0.087$ for subadults (ages $1-4$ ), $0.919 \pm 0.044$ for adult females, and $0.917 \pm 0.041$ for adult males. Abundance in the last $3 \mathrm{yr}$ of study was $1,592 \pm$ 361 bears. Mean size of newborn litters was $1.648 \pm 0.098$ cubs. By age 7, $0.97 \pm$ 0.30 of available females were producing litters. Harvest averaged $38.4 \pm 4.2$ bears/year in the last $5 \mathrm{yr}$ of study; however, the 2002-2007 kill averaged
\end{abstract}


56.4 bears/yr. We used a harvested Population Viability Analysis (PVA) to examine impacts of increasing rates of harvest. We estimated the current population growth rate, $\lambda_{H}$, to be $1.025 \pm 0.032$. Although this suggests the population is growing, progressive environmental changes may require more frequent population inventory studies to maintain the same levels of harvest risk.

Key words: demography, mark-recapture, polar bear, Ursus maritimus, Population Viability Analysis (PVA), program MARK, harvest.

In recent years, concerns about climate warming have dominated discussions about the conservation of polar bears (Ursus maritimus) and predicted trends in populations (Derocher et al. 2004, Hassol 2004, IUCN 2006, COSEWIC 2008). Although climate may ultimately determine the future distribution of the species, over the past $30 \mathrm{yr}$ the vast majority of declines in polar bear populations can be attributed to unsustainable harvesting (e.g., Beaufort Sea and Chukchi Sea, Amstrup et al. 1986; Western Hudson Bay, Derocher and Stirling 1995; Viscount-Melville Sound, Taylor et al. 2002; Baffin Bay, Taylor et al. 2005, Wiig 2005; M'Clintock Channel, Taylor et al. 2006). The hunting of polar bears is of major cultural and economic importance to many northern residents (Freeman and Wenzel 2006); hence, at least in the short term (e.g., the next 10-15 yr), hunting is likely to continue to play the major role in determining trends of polar bear populations.

To avoid hunting unsustainably, yet maximize removals, the general approach has been to develop deterministic models of abundance and yield; however, from a deterministic perspective, there is only one rate of harvest that will stabilize a population at its current number and be sustainable indefinitely. Determining harvests that are sustainable depends upon a number of factors, including abundance, natural rates of birth and death, and the sex and age composition of the harvest (Caughley and Sinclair 1994). Unfortunately, because population size and vital rates are almost always obtained with some degree of error, either through sampling error or observations of process (e.g., environmental) variation, deterministic attempts to calculate sustainable yields underestimate the risk of harvest for managed populations.

Rather than relying on deterministic models to establish sustainable yields, an alternative approach may be to manage for harvests that provide for some reasonable likelihood of population persistence some time into the future. Models of probability of persistence, such as Population Viability Analysis (PVA, review in White 2000), are a rational means by which to incorporate variance of input parameters into harvest models. PVA has the flexibility to provide managers and stakeholders with harvest compositions that are sustainable at a given population size with an associated probability, but also consequences should a harvest later be deemed too severe (e.g., required length of moratorium to restore the population; Taylor et al. 2002, 2005). Further, where links can be made between natural demographic rates and directional climate change (e.g., Western Hudson Bay; Regehr et al. 2007a), harvested PVA models could play an important role in predicting sustainable harvests that track progressive and cyclical changes in population growth and carrying capacity.

Here we use mark-recapture and harvest recovery data collected from 1976 to 2000 for polar bears inhabiting the Gulf of Boothia, Nunavut (Fig. 1), to estimate demographic rates and their variances, abundance, and short-term harvest risks. Our demographic analysis included a detailed assessment of age- and sex-specific survival and recruitment from 630 marked polar bears, using information contained within 


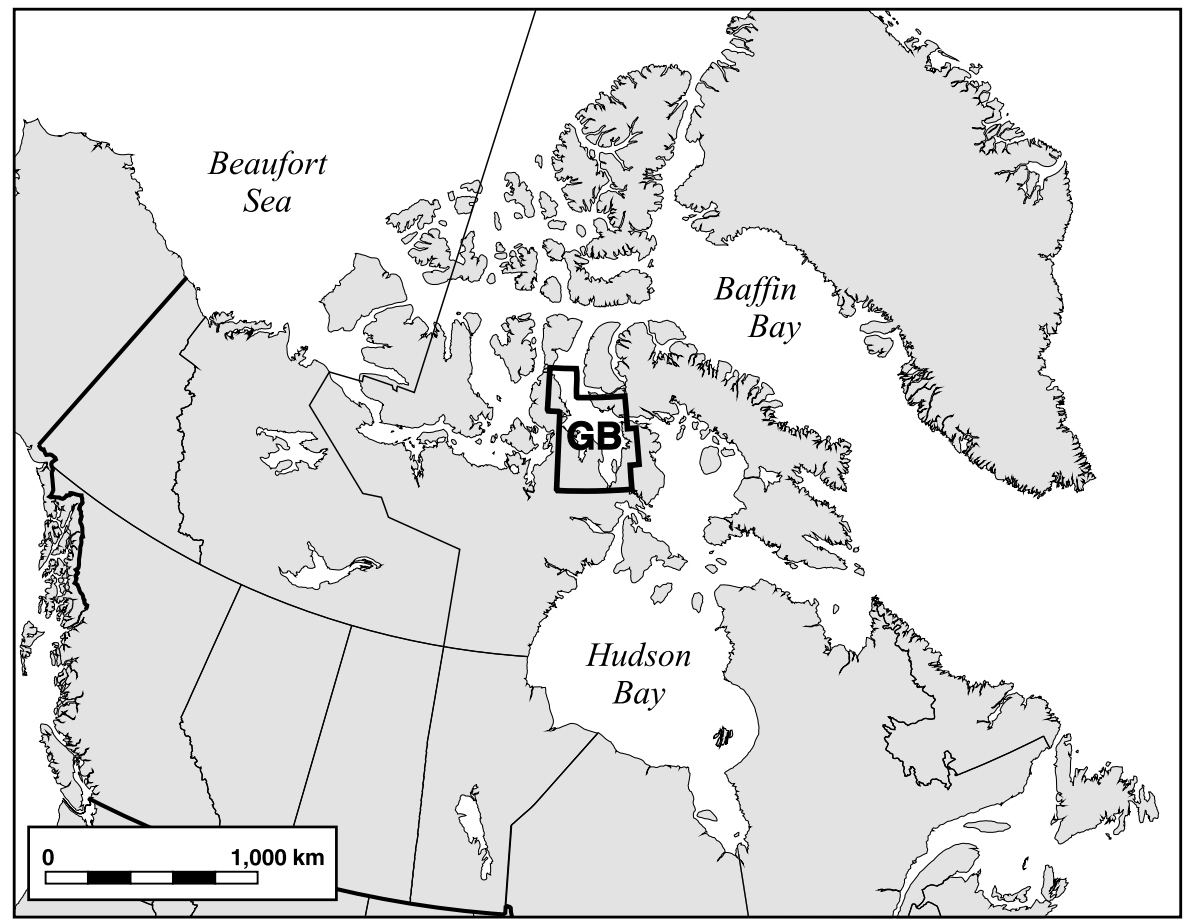

Figure 1. Location of the Gulf of Boothia (GB) polar bear population, Nunavut. Boundaries are defined as in Taylor et al. (2001).

the standing age distribution (Caughley 1977:88) of captures and survival and abundance estimates from mark-recapture analysis. We then incorporated demographic parameters and their variances into a harvest risk analysis to generate likelihoods of persistence under the current harvest regimen to estimate the short-term (20002015) sustainability of the hunt (i.e., a harvested PVA).

\section{METHODS}

Study Area

Geographic bounds of the Gulf of Boothia polar bear population (Fig. 1) were previously evaluated from movements of marked and/or radio-collared animals from the Gulf of Boothia and adjacent populations (Taylor et al. 2001). These bounds have generally been supported by DNA analysis (Paetkau et al. 1999). Our study area corresponds to the Gulf of Boothia polar bear population identified in Taylor $e t$ al. (2001).

\section{Captures, Recaptures, and Recoveries}

There have been three main capture programs in the Gulf of Boothia yielding data for use in this study (Table 1). The first effort (1976-1978) was part of a general polar 


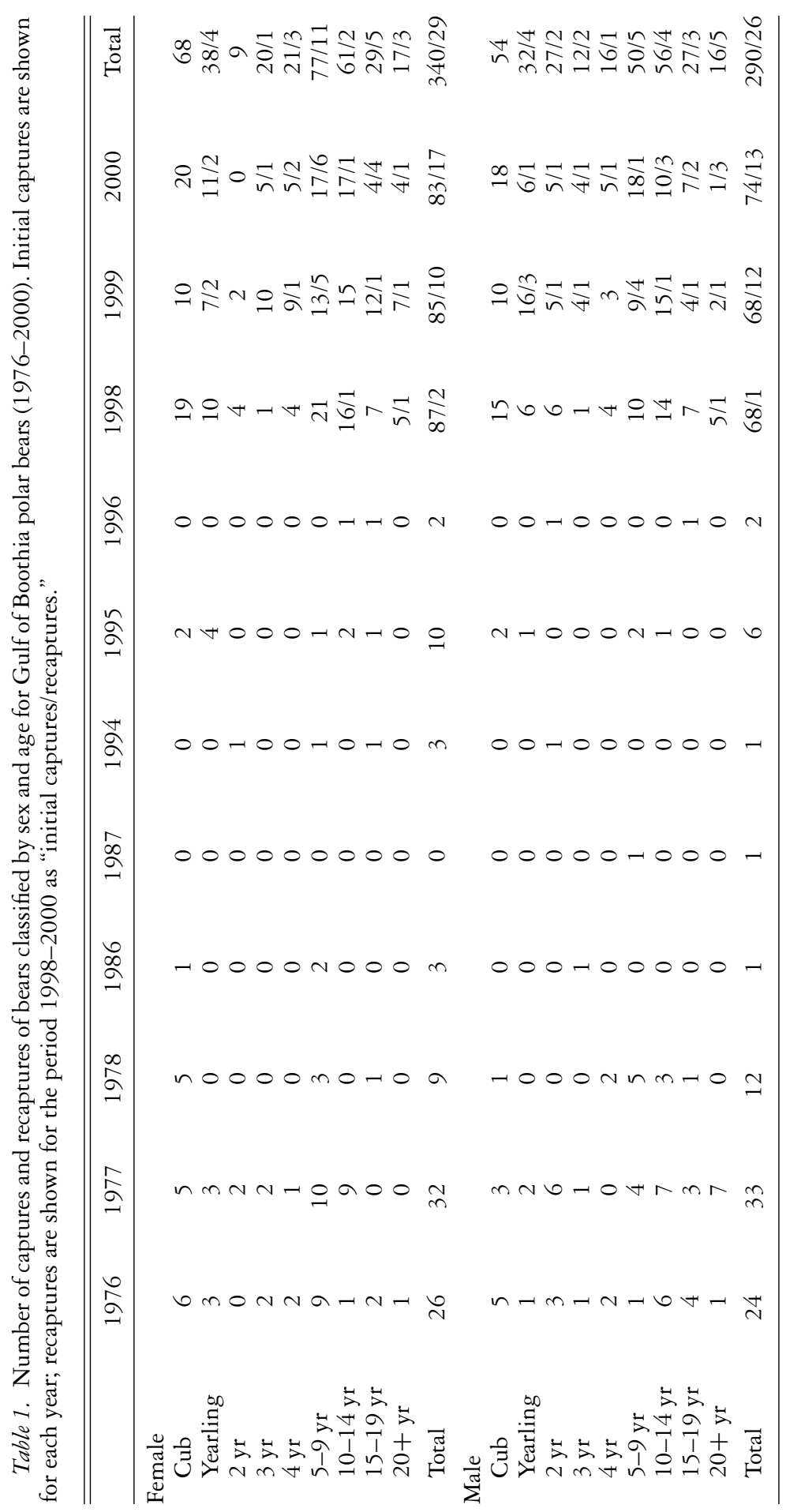


bear study conducted in the Canadian central Arctic in the mid 1970s (Schweinsburg et al. 1981, 1982; Furnell and Schweinsburg 1984) and included only the north and west portion of the Gulf of Boothia. For a brief period from 1986 to 1987, a limited number of polar bears $(n=5)$ were also captured along coastal areas in the study area (Table 1). The most recent capture program was conducted from 1994 to 2000, during which capture effort was directed evenly across the entire study area. From 1994 to 1996 the main priority was uniform deployment of satellite-radio collars on adult females over the study area. Captures of other bears occurred only incidentally to the adult females that were given radio collars. The main capture effort was from 1998 to 2000, during which every bear encountered was captured.

We chemically immobilized all bears and their dependent cubs for capture and marking according to procedures described by Stirling et al. (1989), following Animal Care Protocol No. 950005 of the University of Saskatchewan and under guidance of the Canadian Council on Animal Care. Bears captured from 1976 to 1987 were primarily immobilized with Sernylan (Furnell and Schweinsburg 1984); bears captured in later years were immobilized with Telazol (Stirling et al. 1989). Upon initial capture, we assigned a unique identification number to each bear and marked the animals accordingly using a plastic ear tag and permanent lip tattoo. We also marked each bear with a wax crayon on the fur to ensure that they were not captured more than once per year. We considered a bear's age as "known" if the bear was captured as a cub-of-the-year (cub) or yearling, or if its age was estimated by counting annular rings of an extracted vestigial premolar (Calvert and Ramsay 1998). The sex, age, family status, and location of all polar bears killed by hunters, killed as problem bears, or found dead from any cause were also recorded.

\section{Survival and Abundance}

Estimates of survival and abundance were constructed from analysis of capturerecapture and harvest recovery data using the Burnham joint live-dead model (Burnham 1993) implemented in program MARK (White and Burnham 1999). We used the RMark interface (Laake and Rexstad 2007) in the R computing environment ( $\mathrm{R}$ Development Core Team 2008) to develop models in MARK. The likelihood for the capture-recapture-recovery data are conditioned on initial capture events (i.e., the initial capture is treated as a release). The probability structure for recapture and recovery events of marked (i.e., previously caught) animals is defined by user-specified models for survival $(S)$ and recapture probabilities $(p)$ that may be expressed as functions of covariates such as sex, age, and time; and probabilities that dead bears are recovered and reported $(r)$, which may also be modified by covariates. Here we fixed the fidelity parameter, $F$, at 1.0; that is, we assumed no permanent emigration from the Gulf of Boothia population.

We used the Gulf of Boothia capture-recapture and harvest data collected from 1976 to 2000. Captures of bears from 1976 to 1996 were used as initial captures, but the recapture and population estimation was restricted to 1998 to 2000 when there was a large-scale capture program with uniform coverage of the entire population. Recapture probability for 1977-1997 was set to zero in order to ignore all recaptures for this interval to avoid bias from capture heterogeneity. Some information about survival was obtained from the potential recaptures in 1998-2000 of these earlier marked bears, but mostly from the harvest recovery data that extended from 1976 to 1999 . The harvest for 2000 was not included because it was not complete at the 
time the data were extracted and analyzed. Inclusion of harvest recovery provided the opportunity to consider models with temporal shifts in survival.

For 1998-2000 data, we examined 10 different submodels for capture probability that incorporated different combinations of potential covariates of year, sex, and age where ages were categorized as cubs $(0 \mathrm{yr})$, subadults $(1-4 \mathrm{yr})$, and adults $(5+\mathrm{yr})$. Because initial capture events are not included in the model, there was no estimated capture probability for cubs and we assumed it was the same as the accompanying adult female for abundance estimation. An additive model with each factor would include five parameters: three for time, one for sex, and one for age. We also considered sex-age interactions in which capture probability was classified across sex and age groups. In the "family" model, the bears were categorized as: (1) yearlings and adult females (family), and (2) ages $2-4$ of both sexes and adult $(5+)$ males. The "sex/age" model split adult males from the age 2-4 groups to create three categories.

For survival and recovery probabilities, we also considered models that included covariates of sex, age, and year. Males were expected to be harvested at a higher rate than females; we expected cubs to have lower survival than noncubs; and annual differences in environmental conditions were likely to create temporal variation in survival. We did not attempt to estimate survival rates for each year from 1976 to 2000 because the data were too sparse. Instead, we allowed for shifts in survival across blocks of time. We split the years in half (Year block1: 1976-1987, 1988-2000) and in thirds (Year block: 1976-1984, 1985-1992, 1993-2000) and compared these models with models assuming a constant survival across time. For age effects, we considered models in which ages were classified as: (1) cubs and noncubs, and (2) cubs, subadults (1-4), and adults $(5+)$. We examined each of those models with an additive sex effect and then considered age-sex interaction models in which the sex effect was restricted to noncubs and another with an adult sex effect (i.e., no sex difference for cubs and subadults). With the five sex-age combinations and 3-yr models (constant, Year block1, Year block) that gave 15 models, we added two sexyear interaction models for each year model for a total of 19 submodels for survival. The same submodel was used for both survival and recovery under the expectation that most factors that affect harvest recovery would affect survival.

Each capture probability submodel was paired with each survival-recovery submodel for a total of 190 models fitted to the data. We used Akaike's Information Criterion adjusted for sample size and overdispersion $\left(\mathrm{QAIC}_{c}\right.$ ) as a guide for model selection (Burnham and Anderson 2002). These data were likely to be overdispersed (i.e., greater than binomial variation) because survival and capture events of family groups (e.g., females with cubs or yearlings) were not independent. We estimated the overdispersion coefficient, $\hat{c}$, based on the number of dependent cub captures $\left(n_{c}\right)$ relative to all captures, $n$ (i.e., $\frac{n}{(n-n)}$; see Appendix in Taylor et al. 2002). We ranked the model with the lowest $\mathrm{QAIC}_{c}$ as best, and we used differences in $\mathrm{QAIC}_{c}$ between the best-fitting model and every other model $\left(\triangle \mathrm{QAIC}_{c}\right)$, in addition to Akaike weights, to identify other likely models (Burnham and Anderson 2002). We computed model-averaged estimates across all 190 models.

We constructed abundance estimates as described by Taylor et al. (2002) and also by McDonald and Amstrup (2001) in which the number captured in year $i\left(n_{i}\right)$ is divided by the estimated recapture probability in year $i\left(\hat{p}_{i}\right)$

$$
\hat{N}_{i}=\frac{n_{i}}{\hat{p}_{i}}
$$


We used the variance estimator in Taylor et al. (2002) which follows the approach of Huggins (1989) and Borchers et al. (1998)

$$
\operatorname{vâr}\left(\hat{N}_{i}\right)=\frac{n_{i}\left(1-\hat{p}_{i}\right)}{\hat{p}_{i}^{2}}+\frac{\hat{N}_{i}^{2}}{\hat{p}_{i}^{2}} \operatorname{vâr}\left(\hat{p}_{i}\right) .
$$

When we stratified the population by age and sex, the total estimated population was the sum of stratum estimates and the variance estimator was extended to include covariances

$$
\begin{aligned}
\hat{N}_{i} & =\sum_{j} \frac{n_{i j}}{\hat{p}_{i j}} \text { and } \\
\operatorname{vâr}\left(\hat{N}_{i}\right) & =\sum_{j} \frac{n_{i j}\left(1-\hat{p}_{i j}\right)}{\hat{p}_{i j}^{2}}+\sum_{j} \sum_{j \prime} \frac{n_{i j} n_{i j \prime}}{\hat{p}_{i j}^{2} \hat{p}_{i j \prime}^{2}} \operatorname{cov}\left(\hat{p}_{i j}, \hat{p}_{i j \prime}\right) .
\end{aligned}
$$

We used a similar estimator to construct a variance estimate for the average population size over several years. The abundance estimates were also model averaged.

Our estimates of total survival $(S)$ derived from capture-recapture data included losses from harvest. We were interested in estimating natural survival, $S_{N}$, to investigate potential impacts of alternative harvest strategies (see Simulations, below). We assumed that all harvested marked bears were reported and estimated natural survival from total survival and recovery as described by Taylor et al. (2005)

$$
\hat{S}_{N}=\hat{S}+(1-\hat{S}) \hat{r}
$$

and

$$
\operatorname{vâr}\left(\hat{S}_{N}\right)=\operatorname{vâr}(\hat{S})(1-\hat{r})^{2}+\operatorname{vâr}(\hat{r})(1-\hat{S})^{2}+2 \operatorname{côv}(\hat{S}, \hat{r})(1-\hat{r})(1-\hat{S}) .
$$

Note that the equation for the variance estimator, Taylor et al. (2005) is missing the exponent 2 for the first term: $\operatorname{var}(\hat{S})(1-\hat{r})^{2}$.

For models with temporal shifts in survival there is no single measure of natural survival, so for each age and sex class we estimated a mean natural survival and process variance using the method described by Burnham and White (2002). To derive final values for natural survival, we model averaged the mean natural survivals and process variance estimates. For models without a year effect we set the process variance to zero.

\section{Reproduction}

We estimated reproductive parameters from the standing age distribution based on captures and recaptures from 1994 to 2000. Each individual or family group was recorded by age as a male, solitary female, female with a cub, female with two cubs, female with a yearling, female with two yearlings, female with a 2-yr-old, or female with two 2-yr-old cubs. Only one female with three cubs was observed. For analysis, we treated this family group as an observation of a female with two offspring.

Our methods for estimating litter size, age-specific litter production rates (for females aged 4, 5, 6, and 7+yr), and sex ratio at birth from the standing age 
distribution are described in Taylor et al. $(1987 a, b ; 2002)$ and available as the software package "Vital Rates" (Taylor et al. 2000). Litter production rates applied only to sexually mature females that would have been available for mating the previous year (i.e., females that did not possess cubs or yearlings [including cases of whole litter loss] in the previous year and females with 2-yr olds). Litter production rate was estimated as the ratio of females with litters of cubs (age 0) plus females with litters of yearlings plus females with litters of 2-yr olds to females with no litters plus females with 2 -yr olds. A correction term for annual litter loss, adult female mortality, and annual population growth rate was applied to the value for females with yearlings and females with 2 -yr olds in the numerator. Litter size of cubs (age 0) was the average litter size of females with cubs (age 0). Variances for recruitment parameters were estimated using the jackknife procedure (Arveson 1969), which involved stratifying standing age distributions by year or pooling years when sample size for individual years was insufficient. Our estimate of variance pooled both sampling error and inter-year environmental variation. Litter production rate estimates were proportions; however, the jackknife estimate is a mean of means and the variance associated is assumed to be normally distributed. Variances of summary reproductive parameters were determined from Monte Carlo simulations with 2,000 iterations.

\section{Simulations: Population Growth Rate and Harvest Risk}

We used Monte Carlo methods to model the population dynamics of the Gulf of Boothia polar bear population assuming that the population was closed, and that the current average reported harvest was constant over the simulation interval (15 yr). The mean and standard error of estimates of the annual survival and reproduction rates described above were assumed to be constant over this period. We computed the expected annual population growth rate $(\lambda)$ for each year of the simulation as the mean of 2000 geometric means of $\lambda$ for each of the $15 \mathrm{yr}$ of the simulation. For this we used the life table- and individual-based population simulation program "RISKMAN" (Taylor et al. 2003; see also Dobey et al. 2005, McLoughlin et al. 2005, Wear et al. 2005, Clark and Eastridge 2006, Howe et al. 2007). We used RISKMAN to estimate $\lambda$ because it provides an option to specifically model the population dynamics of species with multiyear reproductive schedules, such as bears, cetaceans, elephants, pinnipeds, and primates (Taylor et al. 1987a, b). Our simulation stipulated 30 age classes and the following sex and family status categories: males, females with no young, females with one or two newborns, females with one or two yearlings, and females with one or two 2 -yr olds. In addition to age and sex-specific reproduction, ageand sex-specific survival, maximum age of life (i.e., $30 \mathrm{yr}$ ), and minimum and maximum ages of reproduction are required inputs of the model. In each year of simulation, the age-specific recruitment rate $\left(m_{x}\right)$ is estimated as a function of three components: the availability of a female in year $x-1$ to mate and produce offspring the following year (which is dependent on reproductive cycle), litter production rate of mating females, and litter size of recruits at the time of census. We thus computed population growth rate from the net reproductive rate taking into account multiannual parental care (see Taylor et al. 1987a ,b, 2003 for mathematical details). Simulations were time referenced to the last year of study (2000). We used a starting population size that was the average of the 1998-2000 population estimates obtained from mark-recapture analysis. 
We estimated two rates of population growth: the geometric mean annual, zeroharvest population growth rate $\left(\lambda_{N}\right)$ and the mean harvested (i.e., total) population growth rate $\left(\lambda_{H}\right)$. The zero-harvest population growth rate was the growth rate of that component of the population that died of natural mortality only. We described variability about $\lambda$ by presenting the standard deviation (SD) of $\lambda$ after 2,000 stochastic simulations (i.e., standard error [SE]; Manly 1997); our approach to variance and model stochasticity is described below. Only the population growth rate $(\lambda)$ at year 15 is reported.

RISKMAN models the uncertainty of population parameter input estimates in a manner consistent with a birth-pulse annual life table model (Caughley 1977, Taylor et al. 2003). Sampling error in initial population size, variance about vital rates due to sample size and annual environmental variation (survival, reproduction, sex ratio), and demographic stochasticity are considered. To incorporate uncertainty in initial population size, simulations were generated using a random initial population size $\left(N_{i}\right)$ drawn from a normal distribution with mean and SE from our mark-recapture estimates. For each year of simulation, RISKMAN obtains a random normal deviate for each survival and recruitment rate based on the specified mean and SE for particular sex and age strata. Individuals in the model are then exposed in a series of Bernoulli trials to the probabilities provided as annual random deviates. This process was designed to incorporate both annual variability and sampling error (see description of variance partitioning, below), including uncertainty associated with applying the random mean to individual trials where the result is either a success or a failure (e.g., survival or death, produce a litter or fail to produce a litter). The Monte Carlo methods (Manly 1997) incorporated in RISKMAN generate a distribution of results, which can then be used to estimate population size at a future time, population growth rate, and proportion of runs that result in a population decline set at a predetermined level by the user. In addition to using RISKMAN to estimate population growth rate, we used proportions of simulation runs that resulted in population declines to estimate persistence probability to assess the future risk (likelihood of sustainability) of past, current, and potential future harvest regimens (i.e., a harvested PVA, below).

We were able to estimate the proportions of sampling and environmental variance separately for mean survival rates; however, our estimator of variances for reproductive parameters was from a jackknife nonparametric procedure that did not permit quantitative partitioning of the sampling environmental variance components. RISKMAN allows a single user-defined partitioning of total variance to sampling and environmental variance, but does not currently support unique partitioning of variance for the various sex/age strata of all vital rates. Our simulated estimates of $\lambda$ assumed a partitioning of sampling $v$ s. environmental variance of 0.95 as sample variance and 0.05 as environmental variance. This division was guided by estimates of the relative proportions of sample and environmental variance for mean survival rates (Table 4). Thompson et al. (1998) notes that parameter (sampling) uncertainty has a larger effect on simulations than environmental uncertainty, so increasing the portion that is assigned to sampling uncertainty will result in higher estimates of risk. Sampling error in initial population size was simulated by obtaining a Monte Carlo deviate from the mean and sample component of the total variance at year zero of each simulation, which carried through the simulation interval (Taylor et al. 2003). Environmental (process) variance was simulated by obtaining a Monte Carlo deviate from the sample error deviate value and the environmental 
component of total variance for each year of the simulation interval (i.e., annual iterations).

To examine population viability, the frequency of occurrence of unacceptable outcomes (based on a threshold value of decline of $>20 \%$ of initial population size) was monitored and reported as the cumulative proportion of total runs over the threshold after $15 \mathrm{yr}$. We chose to conduct model projections using these criteria because: (1) the population inventory cycle for this population is currently planned to be $15 \mathrm{yr}$ in duration, (2) we do not advocate using PVA over long time periods in view of potential significant changes to habitat regarding climate change in the Arctic, and (3) we thought most readers would appreciate a $>20 \%$ decline in population size over $15 \mathrm{yr}$ as an unacceptable outcome. For comparison, we also present the probability of any decline over the period of simulation (in which case 1 minus this value represents the likelihood of population increase).

The standing age distribution contained more females than males due to long-term selective harvest of males (Table 1). Because we wished to err on the side of caution, for all simulations we used the stable age distribution expected to be achieved by the population as the initial age/sex distribution because initializing the population at the stable age distribution produced more higher-risk estimates compared to initializing with the observed or projected standing age distribution). We identified a harvest selectivity and vulnerability array by comparing the standing age distribution of the historical harvest to the total mortality, stable age distribution. Harvest was stratified by sex, age (cubs and yearlings, age $2-5$, age $6-19$, and age $>20$ ) and family status (alone, or with cubs and yearlings, or with 2 -yr olds). To examine effects of a range of harvest levels on risk of population decline, we ran harvest simulations using natural survival rates upon which we added incrementally increasing rates of harvest (i.e., human-caused mortality from all sources; $0-100$ bears/year). The RISKMAN manual and online help file (Taylor et al. 2003) provides a comprehensive description of the model structure and approach to variance estimation and applications to harvest risk management. The RISKMAN simulation model and documentation is available free at http://riskman.nrdpfc.ca/riskman.htm.

\section{RESULTS}

\section{Captures, Recaptures, and Recoveries}

From 1976-2000, 630 unique polar bears (340 female and 290 male) were captured and marked in the study area (Table 1). Of the 520 bear captures from 1998 to 2000, 55 were recaptures of previously marked bears (Table 1). From the harvest years 1976-1999, 26 female and 31 male marks were recovered in the harvest of the 257 females and 216 males bears marked through 1999 (Tables 1,2). The male recovery percentage of $14 \%$ was slightly higher than the $10 \%$ for females but a sex effect was not strongly supported in the modeling. A more striking difference can be observed in the early $v$ s. late recovery proportions. Of the bears marked from 1976 to $1978,25 \%$ of the females and $29 \%$ of the males were recovered in the harvest from 1976 to 1985 ; whereas of the bears marked in 1998-1999 only $1.7 \%$ and $4.4 \%$ of the females and males, respectively, were recovered. 


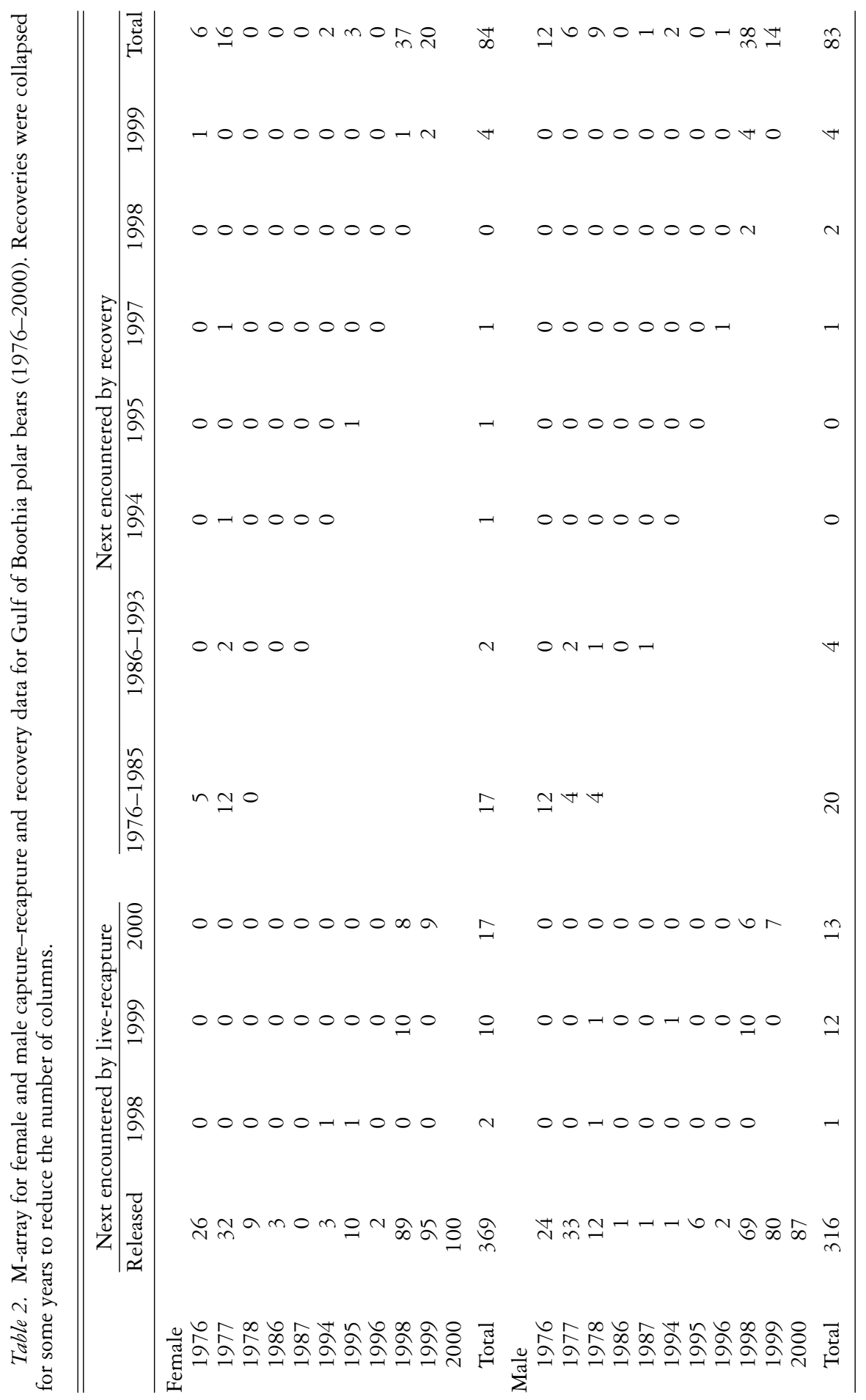


Table 3. Number of parameters (\# par), $\triangle \mathrm{QAIC}_{c}$, and model weight for 20 models with greatest support of the 190 models fitted to the Gulf of Boothia polar bear (1976-2000) capture-recapture and recovery data (see text for definitions of $S, p$, and $r$ ). Year block1 was the 2-period model and Year block was the 3-period model. The term "csa" refers to age classified as cub (0), subadult (1-4), and adult $(5+)$; and "noncub" refers to age classified as cub $(0)$ and noncub $(1+)$. The effects "male:noncub" and "male:adult" refer to a sex effect being limited to that age class. For capture probability, "age.sex" was stratified as (1) yearlings/adult females, (2) ages 2-4, and (3) adult males; whereas "family" was stratified as yearlings/adult females $v$ s. ages 2-4 plus adult males (i.e., the last two categories of age.sex collapsed).

\begin{tabular}{|c|c|c|c|}
\hline Model & \# par & $\Delta \mathrm{QAIC}_{c}$ & Weight \\
\hline$S\left(\sim_{\text {csa }}+\right.$ Year block 1$) p(\sim 1) r\left(\sim_{\text {csa }}+\right.$ Year block 1$)$ & 8 & 0.00 & 0.14 \\
\hline$S(\sim$ noncub + Year block 1$) p(\sim 1) \mathrm{r}(\sim$ Year block 1$)$ & 6 & 1.20 & 0.08 \\
\hline$S\left(\sim_{\text {csa }}+\right.$ Year block 1$) p(\sim$ family $) r\left(\sim_{\text {csa }}+\right.$ Year block 1$)$ & 9 & 1.74 & 0.06 \\
\hline$S\left(\sim_{\text {csa }}+\right.$ Year block 1$) p\left(\sim_{\text {csa }}\right) r\left(\sim_{\text {csa }}+\right.$ Year block 1$)$ & 9 & 1.86 & 0.06 \\
\hline$S\left(\sim_{\text {csa }}+\right.$ Year block 1$) p\left(\sim_{\text {sex.age })} r\left(\sim_{\text {csa }}+\right.\right.$ Year block 1$)$ & 10 & 2.20 & 0.05 \\
\hline$S(\sim$ noncub + Year block 1$) p(\sim$ family $) r(\sim$ Year block 1$)$ & 7 & 2.76 & 0.04 \\
\hline $\begin{array}{l}S(\sim \text { csa }+ \text { adult:male }+ \text { Year block } 1) p(\sim 1) r(\sim \text { csa }+ \\
\quad \text { adult:male }+ \text { Year block } 1)\end{array}$ & 10 & 2.88 & 0.03 \\
\hline$S\left(\sim_{\text {noncub }}+\right.$ Year block 1$) p\left(\sim_{\text {csa }}\right) r(\sim$ Year block 1$)$ & 7 & 3.13 & 0.03 \\
\hline$S(\sim$ noncub + Year block 1$) p(\sim$ sex.age $) r(\sim$ Year block 1$)$ & 8 & 3.17 & 0.03 \\
\hline$S\left(\sim_{\text {csa }}+\right.$ Year block 1$) p(\sim$ time $) r\left(\sim_{\text {csa }}+\right.$ Year block 1$)$ & 10 & 3.28 & 0.03 \\
\hline$S\left(\sim_{\text {csa }}+\right.$ Year block 1$) p\left(\sim_{\text {sex }}+\right.$ csa $) r\left(\sim_{\text {csa }}+\right.$ Year block 1$)$ & 10 & 3.53 & 0.02 \\
\hline $\begin{array}{l}S\left(\sim_{\text {csa }}+\text { sex }+ \text { Year block } 1\right) p(\sim 1) r\left(\sim_{\text {csa }}+\text { sex }+ \text { Year }\right. \\
\quad \text { block } 1)\end{array}$ & 10 & 3.93 & 0.02 \\
\hline $\begin{array}{l}S\left(\sim_{\text {csa }}+\text { male:noncub }+ \text { Year block } 1\right) p(\sim 1) r\left(\sim_{\text {csa }}+\text { sex }+\right. \\
\quad \text { Year block } 1)\end{array}$ & 10 & 4.02 & 0.02 \\
\hline$S(\sim$ noncub $) p(\sim 1) r(\sim 1)$ & 4 & 4.18 & 0.02 \\
\hline$S\left(\sim_{\text {csa }}+\right.$ Year block $) p(\sim 1) r\left(\sim_{\text {csa }}+\right.$ Year block $)$ & 10 & 4.25 & 0.02 \\
\hline$S(\sim$ noncub + Year block 1$) p(\sim$ time $) r(\sim$ Year block 1$)$ & 8 & 4.50 & 0.01 \\
\hline $\begin{array}{l}S(\sim \text { csa }+ \text { adult: male }+ \text { Year block } 1) p(\sim \text { csa }) r(\sim \text { csa }+ \\
\quad \text { adult:male }+ \text { Year block } 1)\end{array}$ & 11 & 4.77 & 0.01 \\
\hline $\begin{array}{l}S(\sim \text { csa }+ \text { adult:male }+ \text { Year block } 1) p(\sim \text { family }) r(\sim \text { csa }+ \\
\text { adult:male }+ \text { Year block } 1)\end{array}$ & 11 & 4.78 & 0.01 \\
\hline$S(\sim$ noncub + Year block 1$) p(\sim$ sex + csa $) r(\sim$ Year block 1$)$ & 8 & 4.82 & 0.01 \\
\hline$S\left(\sim_{\mathrm{Csa}}\right) p(\sim 1) r\left(\sim_{\mathrm{Csa}}\right)$ & 6 & 5.02 & 0.01 \\
\hline
\end{tabular}

\section{Survival and Abundance}

For model selection, we used $\hat{c}=1.181$. The number of parameters for the 190 models ranged from 4 to 20 and the maximum $\Delta$ QAIC $_{c}$ was 22.0. The top 20 models (Table 3) accounted for $69 \%$ of the model weight. There was strong support for differences in survival based on cub, subadult (1-4), and adult (5+) classes or cub/noncub classes. There was also strong support for different survival rates between the first and latter halves of the study period. However, there was little support for differences within/among the sexes in survival or recovery, with the possible exception of adult males. There was some variation in capture probability with sex and age but more support for a constant probability over time and for all classes.

Annual mean total survival rates $(S)$ were $0.889 \pm 0.179(\bar{x} \pm 1 \mathrm{SE})$ for cubs, $0.883 \pm 0.087$ for subadults, $0.919 \pm 0.044$ for adult females, and $0.917 \pm 0.041$ 
Table 4. Model-averaged estimates and total standard errors (in parentheses) of annual total survival $(S)$, annual natural survival $\left(S_{N}\right)$, and recovery probability $(r)$ for age-sex classes of polar bears in the Gulf of Boothia (1976-2000). Survival estimates are given for the three periods 1976-1984, 1985-1992, and 1993-2000 and as an overall mean for 1976-2000. The percentage of the total variance that was parameter variance and the percent that was process variance is indicated for the mean survival values.

\begin{tabular}{|c|c|c|c|c|c|c|c|}
\hline \multicolumn{2}{|c|}{ Class } & \multirow{2}{*}{$\begin{array}{c}\text { Mean } \\
0.889 \\
(0.179)\end{array}$} & \multirow{2}{*}{$\begin{array}{c}\% \\
\text { parameter }\end{array}$} & \multirow{2}{*}{$\begin{array}{c}\% \\
\text { process }\end{array}$} & \multirow{2}{*}{$\begin{array}{c}1976-1984 \\
0.791 \\
(0.469)\end{array}$} & \multirow{2}{*}{$\begin{array}{c}1985-1992 \\
0.889 \\
(0.215)\end{array}$} & \multirow{2}{*}{$\begin{array}{c}1993-2000 \\
0.889 \\
(0.185)\end{array}$} \\
\hline$S$ & Cub & & & & & & \\
\hline & Subadult & $\begin{array}{c}0.883 \\
(0.087)\end{array}$ & 83.9 & 16.1 & $\begin{array}{c}0.703 \\
(0.128)\end{array}$ & $\begin{array}{c}0.875 \\
(0.094)\end{array}$ & $\begin{array}{c}0.911 \\
(0.076)\end{array}$ \\
\hline & Adult female & $\begin{array}{c}0.919 \\
(0.044)\end{array}$ & 94.9 & 5.1 & $\begin{array}{c}0.852 \\
(0.037)\end{array}$ & $\begin{array}{c}0.917 \\
(0.047)\end{array}$ & $\begin{array}{c}0.950 \\
(0.049)\end{array}$ \\
\hline & Adult male & $\begin{array}{c}0.917 \\
(0.041)\end{array}$ & 94.1 & 5.9 & $\begin{array}{c}0.849 \\
(0.038)\end{array}$ & $\begin{array}{c}0.915 \\
(0.044)\end{array}$ & $\begin{array}{c}0.950 \\
(0.048)\end{array}$ \\
\hline$S_{N}$ & Cub & $\begin{array}{c}0.889 \\
(0.179)\end{array}$ & 100 & 0 & $\begin{array}{c}0.791 \\
(0.469)\end{array}$ & $\begin{array}{c}0.889 \\
(0.215)\end{array}$ & $\begin{array}{c}0.889 \\
(0.185)\end{array}$ \\
\hline & Subadult & $\begin{array}{c}0.897 \\
(0.078)\end{array}$ & 80.0 & 20.0 & $\begin{array}{c}0.759 \\
(0.128)\end{array}$ & $\begin{array}{c}0.887 \\
(0.088)\end{array}$ & $\begin{array}{c}0.947 \\
(0.079)\end{array}$ \\
\hline & Adult female & $\begin{array}{c}0.955 \\
(0.036)\end{array}$ & 92.5 & 7.5 & $\begin{array}{c}0.913 \\
(0.028)\end{array}$ & $\begin{array}{c}0.953 \\
(0.041)\end{array}$ & $\begin{array}{c}0.973 \\
(0.042)\end{array}$ \\
\hline & Adult male & $\begin{array}{c}0.955 \\
(0.035)\end{array}$ & 92.0 & 8.0 & $\begin{array}{c}0.912 \\
(0.028)\end{array}$ & $\begin{array}{c}0.952 \\
(0.039)\end{array}$ & $\begin{array}{c}0.973 \\
(0.041)\end{array}$ \\
\hline$r$ & Cub & & & & 0 & 0 & 0 \\
\hline & Subadult & & & & $\begin{array}{c}0.219 \\
(0.124)\end{array}$ & $\begin{array}{c}0.215 \\
(0.125)\end{array}$ & $\begin{array}{c}0.461 \\
(0.502)\end{array}$ \\
\hline & Adult female & & & & $\begin{array}{c}0.411 \\
(0.090)\end{array}$ & $\begin{array}{c}0.425 \\
(0.158)\end{array}$ & $\begin{array}{c}0.649 \\
(0.409)\end{array}$ \\
\hline & Adult male & & & & $\begin{array}{c}0.416 \\
(0.087)\end{array}$ & $\begin{array}{c}0.431 \\
(0.154)\end{array}$ & $\begin{array}{c}0.654 \\
(0.403)\end{array}$ \\
\hline
\end{tabular}

for adult males (Table 4). There was no harvest recovery of cubs so natural survival is total survival. For subadults, annual mean natural survival rate $\left(S_{N}\right)$ was $0.897 \pm$ 0.078 , and for adult females $0.955 \pm 0.036$ and adult males $0.955 \pm 0.035$ (Table 4). Survival rates were lowest during the first third of the study and highest in the last third (Table 4). Estimated survival for cubs seems high but is consistent with the data. The ratio of the number of yearlings from 1999 to 2000 to the number of cubs from 1998 to 1999 (Table 1) was 0.89 (48/54). Assuming no difference in capture probability for the two groups and years this is a semi-independent estimate of cub survival. However, in general, the precision was poor for cub survival particularly for the earlier period when only harvest recovery provided information on survival. The high sampling variance led to an estimate of zero for the process standard deviation (Table 4).

Recovery probabilities $(r)$ were higher for adults than subadults and were higher during the later periods of study (Table 4), despite an overall decrease in proportion of marks appearing in the harvest (note that harvest proportion is $[1-S] r$ ). For example, for adult females an estimated $6.0 \%$ were harvested annually from 1976 to 1984 and only $3.2 \%$ for $1993-2000$; however, recovery probabilities for these contrasting periods were 0.411 and 0.649 , respectively (Table 4 ). 
Model-averaged estimates of capture probability ranged from 0.097 to 0.114 for the various sex-age classes across years. Annual estimates of total abundance were $1,464 \pm 401(\bar{x} \pm 1 \mathrm{SE}$ ) for $1998,1,577 \pm 358$ for 1999 , and $1,741 \pm 381$ for 2000 with a mean of 1,592 bears \pm 361 , of which $868 \pm 212$ were females and $724 \pm$ 184 were males.

\section{Reproduction}

Summary reproductive parameters for the Gulf of Boothia population based on analysis of the standing age distribution for captures from 1994 to 2000 included means for litter size of cubs $(1.648 \pm 0.098[\bar{x} \pm 1 \mathrm{SE}])$, female litter production rates (females available for mating only) for ages $4(0.00 \pm 0.00), 5(0.19 \pm 0.18)$, $6(0.47 \pm 0.17)$, and $7+(0.97 \pm 0.30)$, and the proportion of newborn males in litters $(0.46 \pm 0.09)$.

\section{Population Growth Rate}

We calculated the stable-age, zero-harvest population growth rate, $\lambda_{N}$, to be $1.065 \pm 0.010(\bar{x} \pm 1 \mathrm{SE})$ using rates of recruitment and natural survival during the period of study. The harvest between 1974 and 2000 was selective for male bears (Table 1) and averaged 38.4 bears/yr $(\mathrm{SE}=4.2)$ from 1995 to 2000. The current harvest is 56.4 bears per year (2002-2007 mean kill; COSEWIC 2008). We estimated the current harvested population growth rate, $\lambda_{H}$, to be $1.025 \pm 0.032$.

\section{Harvest Risk Analysis}

Our results suggest the past harvest of Gulf of Boothia polar bears was sustainable and that current increases in the harvest quota ( 74 bears/yr) will likely be sustainable, at least over the short term. For the period 2000-2015, assuming all sources of removals in the population sum to 74 bears/yr, the population can be expected to persist at a stable population size (Fig. 2). It is only at higher rates of harvest (e.g., $80-100$ bears/yr) that likelihoods of unacceptable outcomes increases to levels that may be cause for concern (Fig. 2).

\section{DisCUSSION}

Our results suggest that adult male and female polar bears in the Gulf of Boothia had approximately the same total survival rate. Previous research on adjacent populations of polar bears (using the same or similar methods as in this study) detected sex effects in the survival of adults (Taylor et al. 2002, 2005, 2006, $2008 a, b)$. However, polar bears in the Gulf of Boothia had not been harvested to the same extent as adjacent populations. Our results suggest population size had increased steadily under a harvest regimen of approximately 40 bears/yr. Despite preference for males in the harvest, the annual harvest rate $(<2.5 \%)$ may have been too low to influence marked differences in overall survival rates among sexes.

Natural survival rates for male polar bears are generally lower than that observed for females (Amstrup 2003). However, our estimates of sex-specific adult survival were 


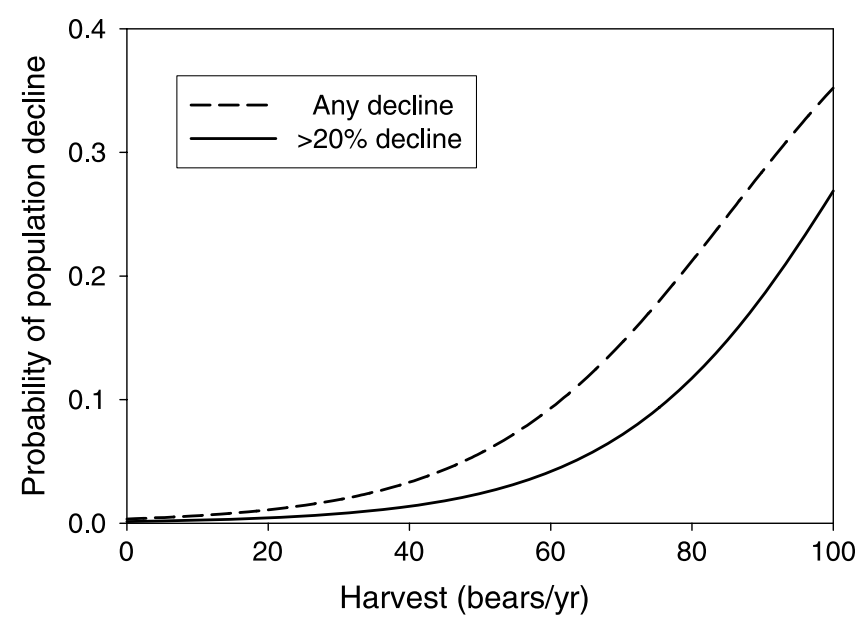

Figure 2. Estimated probabilities of any decline (where 1 minus this value is the probability of population increase) and $>20 \%$ decline from initial population size $v$ s. annual kill for polar bears inhabiting the Gulf of Boothia, Nunavut, 2000-2015. The total removal rate currently legislated by the Government of Nunavut for the population is 74 bears/yr at two males per female, and the 5-yr average removal rate was 56.4 bears/yr (2002-2007).

not different (Table 4). Our observed unharvested stable-age finite rate of increase $\left(\lambda_{N}=1.065\right)$ reflected the relatively high survival and recruitment rates for the Gulf of Boothia population, which may be close to the maximum observed for polar bears (reviews in IUCN 2006 and COSEWIC 2008). For example, our estimate of $\lambda_{N}$ was higher than that estimated for polar bears in Baffin Bay $\left(\lambda_{N}=1.055\right.$; Taylor $e t$ al. $2005)$ to the east and Kane Basin to the northeast $\left(\lambda_{N}=1.009\right.$; Taylor et al. 2008a), and Lancaster Sound $\left(\lambda_{N}=1.023\right)$ and Norwegian Bay $\left(\lambda_{N}=1.001\right)$ to the north (Taylor et al. 2008b). The unharvested population growth rate for bears in the Gulf of Boothia was also higher than for polar bears in the Viscount-Melville Sound $\left(\lambda_{N}=\right.$ 1.059; Taylor et al. 2002) and M'Clintock Channel ( $\lambda_{N}=1.031$; Taylor et al. 2006), two populations thought to be reduced substantially below carrying capacity by years of overharvest.

Our estimates of reproductive parameters (e.g., litter size and timing of first reproduction) fall within the general range of published values (COSEWIC 2008). Our estimate of total first-year cub survival was high and more variable $(0.889, \mathrm{SE}=$ 0.179) compared to other populations, which have ranged from as low as 0.374 $(\mathrm{SE}=0.180)$ in Kane Basin in the far north (Taylor et al. 2008a) to as high as 0.749 $(\mathrm{SE}=0.105)$ for female cubs of Lancaster Sound (Taylor $e t$ al. 2008b). The reason for the high natural survival of cubs is not known; however, it may be due to high habitat quality (e.g., summer pack ice) and prey densities, or delayed age of first reproduction.

This population appears to be increasing in spite of historical and contemporary harvest rates (Fig. 2). The maximum sustainable kill (at current population size only) was estimated at approximately 100 bears/yr (i.e., the point at which $50 \%$ of simulations increased and 50\% decreased [after $15 \mathrm{yr}$; Fig. 2). Inuit hunters 
harvesting from the Gulf of Boothia population emphatically agree that polar bear numbers have increased in this area. Our data suggest that the population is capable of sustaining recent quota increases by the Nunavut Wildlife Management Board and the Government of Nunavut to 74 bears/yr from 40 bears/yr. Nonetheless, we advise caution when information is uncertain, because higher harvest rates constitute an increased risk to the population. No mark-recapture analysis of data collected under field conditions is successful in modeling all sources of heterogeneity in capture probabilities and survival probabilities. Unmodeled capture heterogeneity can reduce estimates of survival and population growth rate (Pollock et al. 1990, Pradel et al. 1997, Pledger and Efford 1998, Regehr et al. 2007a). If population numbers were underestimated, harvest mortality based on a comparison of known removals to estimated population number would be overestimated. Overestimating harvest mortality rates would cause natural survival rates to be overestimated (total mortality $=$ natural mortality + harvest mortality).

Our estimates of population growth assume that the environment does vary, but does not assume any time trend or systematic pattern in how it varies. Hence, our projections do not consider habitat deterioration, or transient habitat enhancement that could be associated with climate warming for the simulation period 2000-2015. Barber and Iacozza (2004) found no trends in Gulf of Boothia sea ice conditions or ringed seal habitat suitability indices in the interval 1980-2000. Most of our data were collected between 1998 and 2000, which is too short an interval to discern longterm environmental trends. Given the declines in polar bear population productivity associated with reduced sea ice in the Beaufort Sea (Regehr et al. 2006, 2007b) and Western Hudson Bay (Regehr et al. 2007a), in light of climate change it may be advisable to accelerate the population inventory cycle for the Gulf of Boothia and for all polar bear populations. That said, the observed increase in both total and natural survival rates over time suggests that conditions for polar bears in the Gulf of Boothia improved over the same period that conditions declined in the Beaufort Sea and Western Hudson Bay.

Our risk assessment is an expression of the uncertainty in the demographic process and parameters. We suggest that our results are more realistic than a deterministic sustained yield estimate that does not consider the uncertainty of the underlying information. Both managers and stakeholders must recognize that scientific information rarely provides exact and absolutely correct harvest rates or harvest quota values. Researchers have a responsibility to quantify the uncertainty of their measurements and the uncertainty of their management recommendations.

\section{ACKNOWLEDGMENTS}

Support for this work was provided by the Government of Nunavut, the Government of the Northwest Territories, the Nunavut Wildlife Management Board, the Polar Continental Shelf Project, the University of Saskatchewan, and the U. S. National Marine Mammal Laboratory. We thank the hunters of Cambridge Bay, Gjoa Haven, Taloyoak, and the Kitikmeot Hunters and Trappers Association who contributed their local and traditional knowledge of polar bears, and participated in the work and harvest program. We extend a special thanks to Pat Lyall for the use of his cabin at Fort Ross. S. Atkinson, P. Krizan, and S. Polischuk assisted with field work. M. Kuc was the primary programmer for RISKMAN and contributed to the development of its algorithms. Comments from S. Amstrup and three anonymous reviewers contributed to this paper. 


\section{Literature Cited}

Amstrup, S. C. 2003. Polar bear. Pages 587-610 in G. A. Feldhamer, B. C. Thompson and J. A. Chapman, eds. Wild mammals of North America: Biology, management, and conservation. 2nd edition. John Hopkins University Press, Baltimore, MD.

Amstrup, S. C., I. Stirling AND J. LenTfer. 1986. Size and trends of Alaskan polar bear populations. Wildlife Society Bulletin 14:251-254.

Arveson, J. N. 1969. Jacknifing U-statistics. Annals of Mathematics and Statistics 40:20762100.

BARBER, D. G., AND J. IACOZZA. 2004. Historical analysis of sea ice conditions in M'Clintock Channel and Gulf of Boothia; Implications for ringed seal and polar bear habitat. Arctic. 57:1-14.

Borchers, D. L., W. Zucchini AND R. Fewster. 1998. Mark-recapture models for line transect surveys. Biometrics 54:1207-220.

Burnham, K. P. 1993. A theory for combined analysis of ring recovery and recapture data. Pages 199-213 in J.-D. Lebreton and P. M. North, eds. Marked individuals in the study of bird population. Birkhauser Verlag, Basel, Switzerland.

Burnham, K. P., AND D. R. Anderson. 2002. Model selection and multimodel inference: A practical information-theoretic approach. 2nd edition. Springer-Verlag, New York, NY.

Burnham, K. P., AND G. C. White. 2002. Evaluation of some random effects methodology applicable to bird ringing data. Journal of Applied Statistics 29:245-264.

CAlvert, W., AND M. A. Ramsay. 1998. Evaluation of age determination of polar bears by counts of cementum growth layer groups. Ursus 10:449-453.

Caughley, G. 1977. Analysis of vertebrate populations. John Wiley and Sons, New York, NY.

Caughley, G., And A. R. E. Sinclair. 1994. Wildlife ecology and management. Blackwell Scientific Publications, Cambridge, MA.

Clark, J. D., AND R. EAstridge. 2006. Growth and sustainability of black bears at White River National Wildlife Refuge, Arkansas. Journal of Wildlife Management 70:10941101.

COSEWIC. 2008. COSEWIC assessment and update status report on the polar bear Ursus maritimus in Canada. Committee on the Status of Endangered Wildlife in Canada, Ottawa, ON. vii +75 pp.

Derocher, A. E., AND I. Stirling. 1995. Mark-recapture estimation of population size and survival rates for polar bears in western Hudson Bay. Journal of Wildlife Management 59:215-221.

Derocher, A. E., N. J. Lunn And I. Stirling. 2004. Polar bears in a warming climate. Integrative and Comparative Biology 44:163-176.

Dobey, S., D. B. Masters, B. K. Scheick, J. D. Clark, M. R. Pelton and M. E. Sunquist. 2005. Ecology of Florida black bears in the Okefenokee-Osceola ecosystem. Wildlife Monograph 158:1-41.

Freeman, M. M. R., AND G. Wenzel. 2006. The nature and significance of polar bear conservation hunting in the Canadian Arctic. Arctic 59:21-30.

Furnell, D. J., AND R. E. SChweinsburg. 1984. Population dynamics of central Arctic polar bears. Journal of Wildlife Management 48:722-728.

HAssol, S. J., ED. 2004. Impacts of a warming Arctic: Arctic climate impact assessment. Cambridge University Press, Cambridge, UK.

Howe, E. J., M. E. OBBARD AND J. A. SCHAEFER. 2007. Extirpation risk of an isolated carnivore population under different management scenarios. Journal of Wildlife Management 71:603-612.

Huggins, R. M. 1989. On the statistical analysis of capture experiments. Biometrika 76:3340.

IUCN. 2006. Polar bears: Proceedings of the 14th Working Meeting of the IUCN Polar Bear Specialist Group. IUCN, Gland, Switzerland. 
LAAKE, J. L., AND E. REXSTAD. 2007. RMark-an alternative approach to building linear models. Appendix C in E. Cooch and G. White, eds. Program MARK, "A gentle introduction". Available at http://www.phidot.org/software/mark/docs/book/.

ManLY, B. F. J. 1997. Randomization, bootstrap and Monte Carlo methods in biology. Chapman and Hall, London, UK.

MCDONALD, T. L., AND S. C. AMSTRup. 2001. Estimation of population size using open markrecapture models. Journal of Agricultural, Biological, and Environmental Statistics 6:206-220.

MCLoughlin, P. D., M. K. TAYLOR AND F. Messier. 2005. Conservation risks of male-selective harvest for mammals with low reproductive potential. Journal of Wildlife Management 69:1592-1600.

Paetkau, D., S. C. Amstrup, E. W. Born, W. Calvert, A. E. Derocher, G. W. Garner, F. Messier, I. Stirling, M. K. Taylor, Ø. Wiig and C. Strobeck. 1999. Genetic structure of the world's polar bear populations. Molecular Ecology 8:1571-1584.

Pledger, S., AND M. EFFORD. 1998. Correction of bias due to heterogeneous capture probability in capture-recapture studies of open populations. Biometrics 54:888-898.

Pollock, K. H., J. D. Nichols, J. E. Hines And C. BRownie. 1990. Statistical inference for capture-recapture experiments. Wildlife Monographs 107:1-97.

Pradel, R., J. E. Hines, J.-D. Lebreton AND J. D. Nichols. 1997. Capture-recapture survival models taking account of transients. Biometrics 53:60-72.

R Development Core Team. 2008. R: A language and environment for statistical computing. R Foundation for Statistical Computing, Vienna, Austria. Available at http://www.Rproject.org.

Regehr, E. V., S. C. Amstrup and I. Stirling. 2006. Polar bear population status in the southern Beaufort Sea. U.S. Geological Survey Open-File Report 2006-1337. 20 pp.

Regehr, E. V., N. J. LunN, I. Stirling AND S. C. Amstrup. 2007a. Effects of earlier sea ice breakup on survival and population size of polar bears in western Hudson Bay. Journal of Wildlife Management 71:2673-2683.

Regehr, E. V., C. M. Hunter, H. Caswell, S. C. Amstrup and I. Stirling. 2007b. Polar bears in the southern Beaufort Sea I: Survival and breeding in relation to sea ice conditions, 2001-2006. USGS Alaska Science Center, Anchorage, AK.

Schweinsburg, R. E., D. J. Furnell and S. J. Miller. 1981. Abundance, distribution, and population structure of polar bears in the lower Central Arctic Islands. Wildlife Service Completion Report Number 2. Government of the Northwest Territories, Yellowknife, Northwest Territories, Canada.

Schweinsburg, R. E., L. J. Lee and P. B. Latour. 1982. Distribution, movement, and abundance of polar bears in Lancaster Sound, Northwest Territories. Arctic 35:159169.

Stirling, I., C. Spencer AND D. ANDriasheK. 1989. Immobilization of polar bears (Ursus maritimus) with Telazol in the Canadian Arctic. Journal of Wildlife Diseases 25:159-168.

Taylor, M. K., F. Bunnell, D. DeMaster, R. SChweinsburg and J. Smith. 1987a. ANURSUS: A population analysis system for polar bears (Ursus maritimus). International Conference on Bear Research and Management 7:117-125.

Taylor, M. K., J. S. Carley and F. L. Bunnell. 1987b. Correct and incorrect use of recruitment rates for marine mammals. Marine Mammal Science 3:171-178.

TAYlor, M. K., M. KuC AND D. ABRAHAM. 2000. Vital Rates: Population parameter analysis program for species with three year reproductive schedules. Government of Nunavut, Iqaluit, Nunavut, Canada.

Taylor, M. K., S. Akeeagok, D. Andriashek, W. Barbour, E. W. Born, W. Calvert, S. Ferguson, J. LaAke, A. Rosing-Asvid, I. Stirling and F. Messier. 2001. Delineating Canadian and Greenland polar bear (Ursus maritimus) populations by cluster analysis of movements. Canadian Journal of Zoology 79:690-709.

Taylor, M. K., J. LaAke, H. D. Cluff, M. Ramsay and F. Messier. 2002. Managing the risk from hunting for the Viscount-Melville Sound polar bear population. Ursus 13:185202. 
Taylor, M. K., M. Obbard, B. Pond, M. Kuc and D. Abraham. 2003. RisKman stochastic and deterministic population modeling RISK Management decision tool for harvested and unharvested populations. v. 1.9. Software manual. Ontario Ministry of Natural Resources, Peterborough, Ontario, Canada. Available at http://www.nrdpfc.ca/riskman/riskman.htm.

Taylor, M. K., J. Laake, P. D. Mcloughlin, E. W. Born, H. D. Cluff, S. H. Ferguson, A. Rosing-Asvid, R. Schweinsburg And F. Messier. 2005. Demography and viability of a hunted population of polar bears. Arctic 58:203-215.

Taylor, M. K., J. Laake, P. D. Mcloughlin, H. D. Cluff and F. Messier. 2006. Demographic parameters and harvest-explicit population viability analysis for polar bears in M'Clintock Channel, Nunavut. Journal of Wildlife Management 70:1667-1673.

Taylor, M. K., J. LaAke, P. D. Mcloughlin, H. D. Cluff, E. W. Born, A. Rosing-Asvid AND F. MESSIER. 2008a. Population parameters and harvest risks for polar bears (Ursus maritimus) of Kane Basin, Canada and Greenland. Polar Biology 31:491-499.

Taylor, M. K., J. Laake, P. D. Mcloughlin, H. D. Cluff and F. Messier. 2008b. Markrecapture and stochastic population models for polar bears of the High Arctic. Arctic 61:143-152.

Thompson, W. L., G. C. White and C. Gowan. 1998. Monitoring vertebrate populations. Academic Press, San Diego, CA.

Wear, B. J., R. EASTRIDGE AND J. D. Clark. 2005. Factors affecting settling, survival, and viability of black bears reintroduced to Felsenthal National Wildlife Refuge, Arkansas. Wildlife Society Bulletin 33:1363-1374.

White, G. C. 2000. Population viability analysis: Data requirements and essential analyses. Pages 288-331 in L. Boitani and T. K. Fullers, eds. Research techniques in animal ecology: Controversies and consequences. Cambridge University Press, New York, NY.

White, G. C., And K. P. Burnham. 1999. Program MARK: Survival estimation from populations of marked animals. Bird Study Supplement 46:120-138.

WIIG, Ø. 2005. Are polar bears threatened? Science 309:1814-1815.

Received: 26 October 2008

Accepted: 16 February 2009 